\title{
Howland Award Presentation to Julius B. Richmond ${ }^{1}$
}

\author{
LEON EISENBERG
}

Chairman, Department of Social Medicine, Harvard Medical School, Boston, Massachusetts 02115

I have known Julius B. Richmond for the better part of my life-the better part qualitatively as well as quantitatively; having him for a friend has made my life better. There isn't time to say all I would like to say about Julie. Moreover, if I said it all, it might be dangerous to his health. Julie has been known to respond to praise with an anaphylactic reaction. The only safe thing for me to do is to dispense my encomiums in homeopathic doses.

There is no more telling way to put the accomplishments of his career in perspective than by recalling what Abraham Jacobi said in his 1889 address as the first President of this Society. Jacobi set forth the proposition that: "Questions of public hygiene and medicine are both professional and social." Thus:

\section{Every physician is by destiny ... a citizen of the common- wealth, with many rights and great responsibilities.... The scientific attainments of the physician and his appreciation of the source of evil enable him to strike at its root by advising aid and remedies (1).}

J.B.R.'s career is a dramatic embodiment of Jacobi's vision.

A bit of biography to begin with: Julie is Chicago born and bred. Except for 4 years of service in the U.S. Army Air Force, he remained in the Windy City or its environs until he was 37. When he was 10 , Julie was placed in a boarding school known as Allendale Farm after his mother's death. Our first picture dates from this period. Figure 1 shows him with a prize ewe at the International Livestock Exposition. Julie is the one wearing trousers and shirt. I do not present this bucolic portrait for laughs. Remember it. It will prove to be an important precursor of our protagonist's life work.

Julie attended college at the University of Illinois Urbana campus, returning to the Chicago campus for medical school. To remind you of just how long ago that was, his first year's tuition was $\$ 35$ a semester!

He interned at Cook County Hospital and took his pediatric training at the Municipal Contagious Disease Hospital and the County Children's Hospital, with Air Force service fit in between. He joined the University of Illinois Medical Faculty as Assistant Professor and rose to Professor within a few years. We have time to discuss only one accomplishment from the Illinois days. In 1952, J.B.R. was appointed Chair of the Committee on Instruction. He persuaded his colleagues to come down in favor of a far-reaching reform of the teaching program. Their report called for 1) the integration of teaching across departments, 2) patient contact early in medical school, 3) attention to the role of psychologic and social factors in health and illness, and 4) the teaching of disease prevention and health maintenance. These concepts were so "radical" in the year they were presented that they were voted down by the senior faculty! Some 40 years later, they were to be rediscovered in the American Association of Medical Colleges' General Professional Education of the Physician report.

Presented at the American Pediatrics Society Meeting on May 8, 1990 in Anaheim, CA
Julie was called to Syracuse in 1953 to be the Chair of Pediatrics. He built an outstanding academic department. A portrait from this era of his life is shown in Figure 2. It presents to us the 1961-62 Executive Committee of the Society for Pediatric Research. Seated are Nathan Smith, J.B.R., the Vice President, Fred Robbins, the President that year, Clark West, Forrest Adams, and Edna Sobel; standing are David Gitlin, Floyd Denny, Lytt Gardner, and Sid Segal.

Let me now abandon dating the strata in his academic preferment to scan his research career. I haven't the time and you haven't the patience for me to review the 250 or so articles and books he's written. Table 1 lists some of the topics he has addressed. Instead, I will focus on one aspect of his research portfolio: his approach to mother-infant interaction and child development. The ways in which J.B.R. has responded to the theme of development exemplify Jacobi's aphorism that "the scientific attainments of the physician and his appreciation of the source of evil enable him to strike at its root...."

It all began when Julie was a farm boy. You recall how he was upstaged in front of the camera by that Raphaelesque beauty of a ewe. In studies inspired by his bucolic experience (where the problem of salvaging lambs by the use of goat foster mothers was an important feature of animal husbandry), J.B.R. demonstrated that brief separation of newborn goats from their mothers resulted in significant interference with the specificity of a mother's attachment to her young. Postnatal separation for periods as brief as 1 hour led to indiscriminate nursing of any kid in the herd, a distinctly abnormal behavior for a species in which kidmother ties are highly specific. It was of equal interest that this happened in only half the mothers, indicating a considerable individual variation in maternal capacity, even in ungulates. Julie documented the capacity of sheep and goats to adopt strange kids and lambs, both within and between species. The

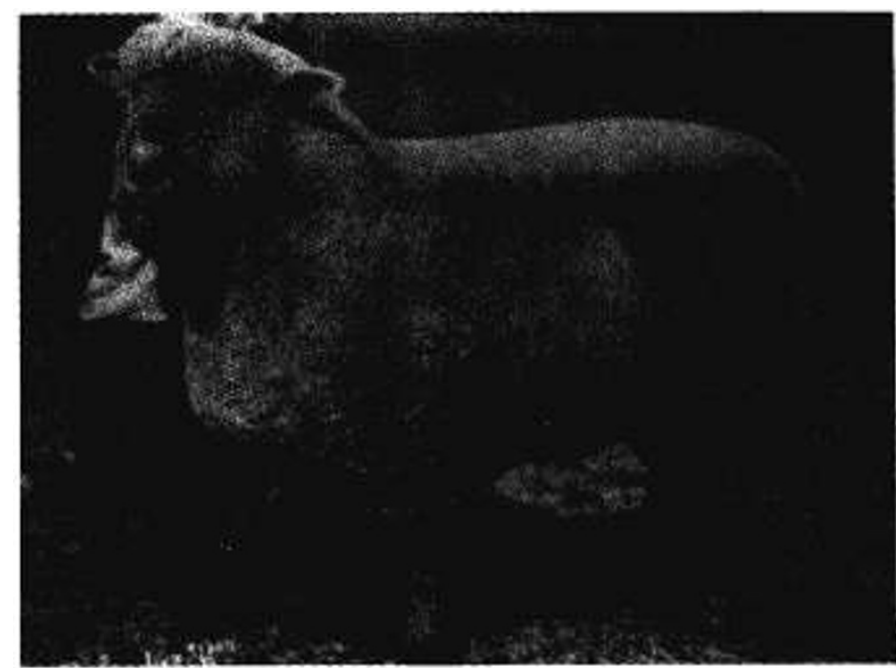

Fig. 1. 


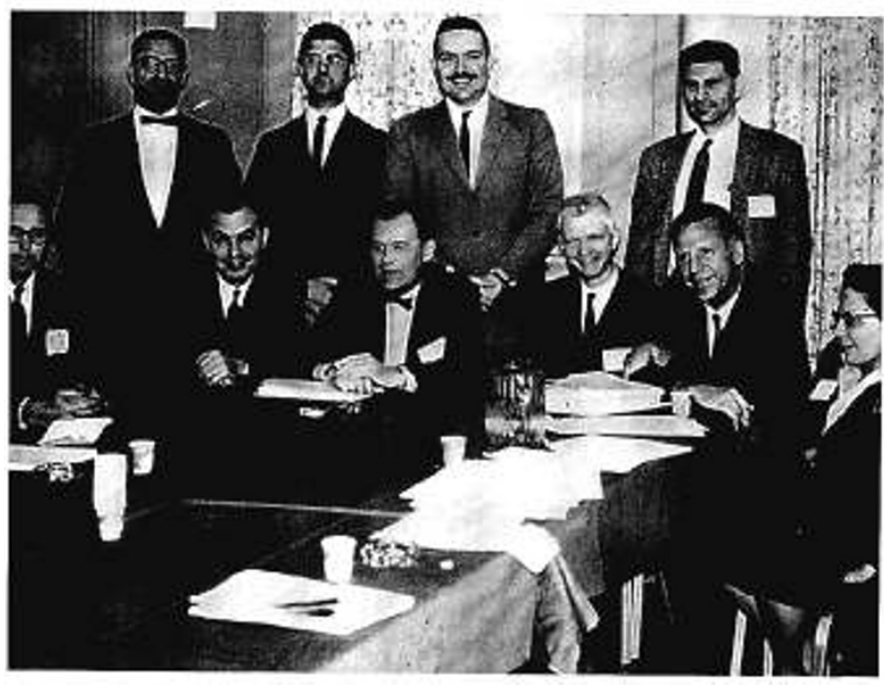

Fig. 2.

Table 1. Sampler of research topics

$\begin{array}{ll}\text { Palindromic Rheumatism } & \text { Pediatric Leukemia } \\ \text { Psychogenic Megacolon } & \text { Rumination in Infancy } \\ \text { Attachment Behavior } & \text { Neonatal Autonomic Function } \\ \text { Infant Swaddling } & \text { Parenting and Social Class } \\ \text { Mental Retardation } & \text { Family of the Handicapped } \\ \text { Preventing Chronic Illness } & \text { Pediatric Teaching } \\ \text { Child Health Policy } & \text { Public Health Strategies }\end{array}$

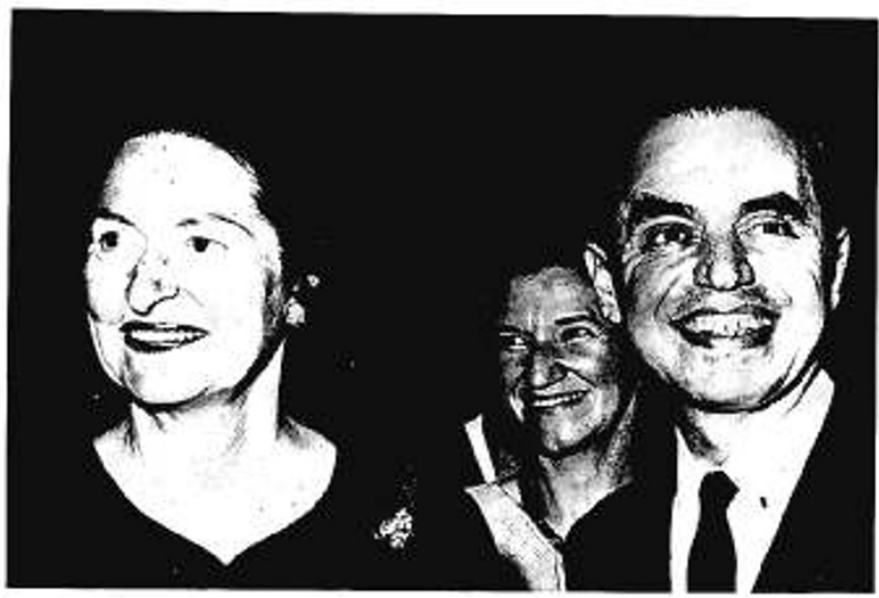

Fig. 3.

arrangements under which the adoptions were attempted had to be delicately managed; without restraint, the mother would destroy the alien offspring; if restrained, she would gradually adapt to its presence and adopt it so that goat and lambs would seek each other's company for the 6 months of juvenile life even in the midst of a flock of sheep (or goats). These studies opened a new avenue of interest in the influence of the infant on the mother, an aspect of mother-infant interaction only latterly coming to the fore in clinical pediatrics and psychiatry.

His animal studies provided the groundwork for major investigations of the developmental patterns of parenting behavior in disadvantaged families. Julie and his colleagues studied the influence of variant patterns of mothering found in lower class homes; namely rearing by multiple mother substitutes (grandmother, aunts, siblings, neighbors). These data, together with developmental studies by the Syracuse group, led to the establishment of a pioneering day care center for infants as young as 6 months of age. This undertaking challenged prevailing official practices and conventional wisdom, which insisted that every infant must

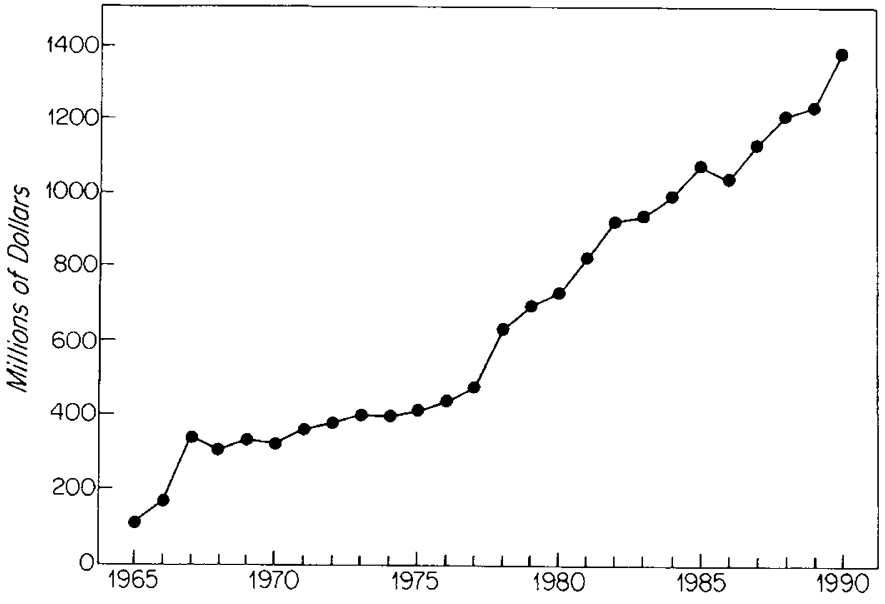

Project Head Start, Statistical Fact Sheet, Januory, 1990

Fig. 4. Head Start federal appropriations.

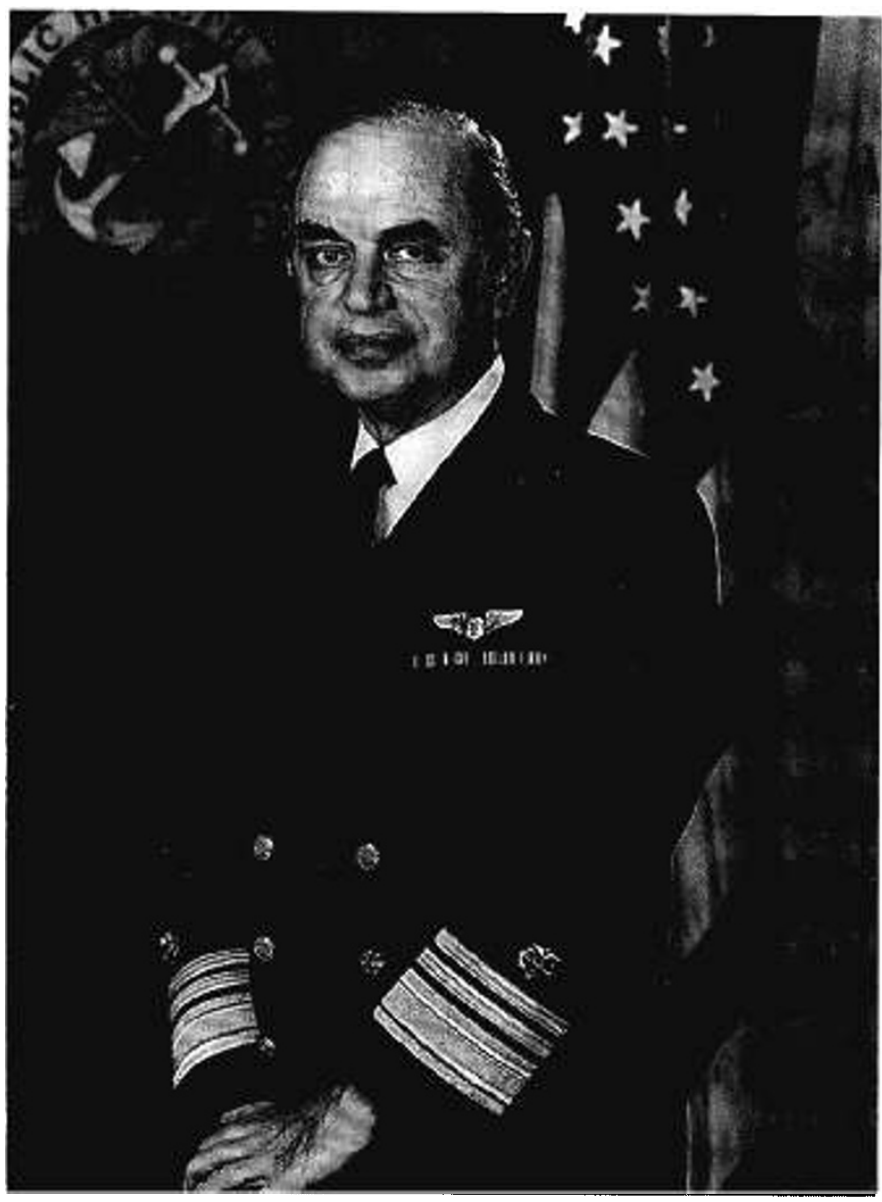

Fig. 5.

remain within his family of origin-despite abundant evidence that many infants fail to thrive in disorganized multiproblem "families." An extensive program of cognitive and emotional stimulation was designed, new personnel were trained (including indigenous community workers), parents were involved, and the unit set into operation. Careful evaluation, based upon the design of new methods, demonstrated significant developmental gains for the experimentals in contrast to control children. Perhaps that should be restated. The experimentals progressed normally; the controls displayed developmental attrition.

Having discovered that the environment of poverty was "the source of evil," Julie was ready to respond to his "destiny [as] a 


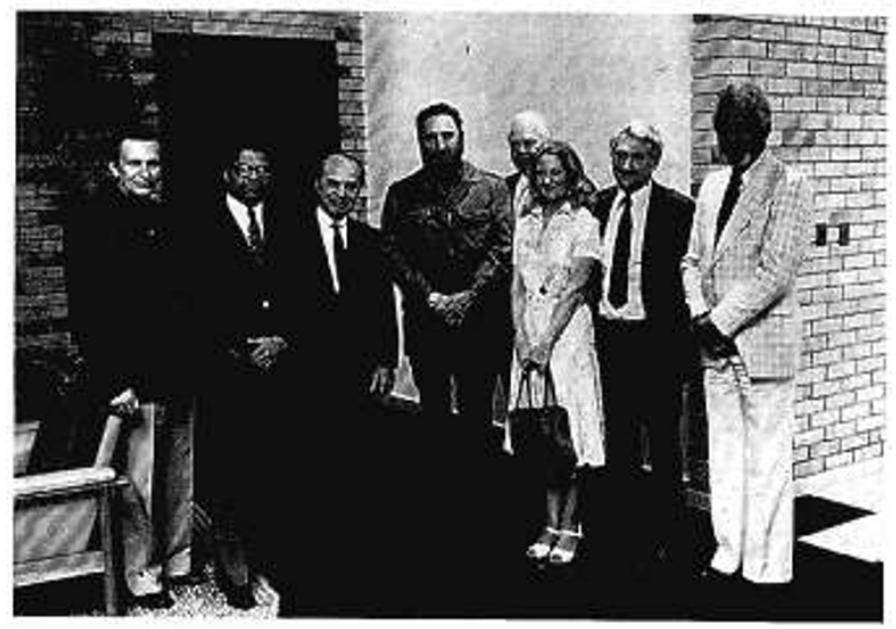

Fig. 6.

citizen of the commonwealth" by accepting a call in 1965 to become National Director of Project Head Start for the Office of Economic Opportunity. With just a few months lead time before the summer Head Start Program was to begin, J.B.R. accomplished a prodigious conceptual and organizational task in mounting a national effort in comprehensive child health and development for some 500,000 American children from poor families. A remarkably successful first summer program was followed by a year-round effort. In addition to educational enrichment, pediatric health surveys identified national needs for this age group. The first major organized efforts to involve parents with their children in preschool programs were undertaken. J.B.R. had the foresight to establish a tradition of volunteerism in Head Start as well as meaningful involvement of parents. A portrait from this era (Fig. 3) portrays him with Lady Bird Johnson at an event celebrating Head Start.

That program has become deeply embedded in American communities. It alone of all the social programs from the War on Poverty has experienced steady increases in federal support. Its funding level is $\$ 1.3$ billion this year, will rise to $\$ 1.9$ billion next year if the President's budget proposal is adopted, and will climb even higher if the day care bill is passed (Fig. 4). Over the past 25 years, more than 12 million preschool children have received preventive as well as curative health services and opportunities for more favorable developmental outcomes. Immunizations have been completed, dental caries and iron-deficiency anemia treated. School readiness, vocabulary, and test taking abilities in the early grades have been improved. Some studies of Head Start "graduates" suggest long-term benefits in the form of fewer placements in special education classes, fewer children repeating grades, better job records, and less antisocial behavior. That, I caution, is more than we have a right to expect. What this nation has yet to do is to commit itself to build on the better beginnings Head Start makes possible by insuring all children quality education in the elementary grades.

Many other important objectives beyond improving the health and welfare of children have resulted. Many parents and other adults with low incomes have received additional education under the auspices of Head Start. High school certificates have been earned and many have gone on to higher education to become staff members of Head Start programs. Communities with Head Start programs have a better record of improving other community services and greater citizen participation in community affairs. Volunteerism has continued and has been a model for other programs.

While serving in the Office of Economic Opportunity, J.B.R., recognizing that "questions of public hygiene are both professional and social," initiated a remarkable and innovative community-based program, the Neighborhood Health Centers, now known as Community Health Centers. In a short period of time, 50 such centers were operating; in the late sixties, the program was transferred to the Department of Health, Education, and Welfare and has grown to more than 800 centers serving between 4 and 5 billion low income people. The program has been characterized by local governance through boards made up of local citizens; it has carried on active outreach efforts to facilitate access by those most in need. It is fair to say that this programalong with Medicare and Medicaid-had much to do with improving access to health services for the poor. In recognition of his outstanding contributions, President Johnson presented Dr. Richmond with a Distinguished Service Award in 1966.

His duties were interrupted by the reactivation of old pulmonary tuberculosis, which responded promptly to 6 months of treatment by bedrest and chemotherapy, a period that Dr. Richmond characteristically used to write a monograph on the history of medical care and education, Currents in American Medicine (2). Once out of bed, he resumed his duties as Dean and Pediatric Chair at Syracuse, one position never having been enough to keep him occupied!

In the fall of 1970 , he became Professor of Child Psychiatry and Human Development at Harvard Medical School, Psychiatrist-in-Chief at the Children's Hospital Medical Center, and Director of the Judge Baker Guidance Center. Before another year had gone, he had been pressed to serve as Chairman of the Department of Preventive and Social Medicine-in addition to, not instead of, his previous triple-threat status! So much for the claim that they don't make all-around football players the way they used to! However, his multiple academic responsibilities did not stand in the way when Julie was asked by President Carter to return to Washington in 1977.

He served for four years as Assistant Secretary for Health and Surgeon General of the United States Public Health Service in the Department of Health and Human Services. The publication in 1979 of his Surgeon General's report Healthy People (3) did much to invigorate the movement for health promotion and disease prevention that he made a centerpiece of federal health policy. He organized a major effort, in conjunction with the staff of the Centers for Disease Control, to define quantitative goals for the nation. These goals are set out in the report Promoting Health and Preventing Disease: Objectives for the Nation (4). This process of defining quantitative targets has now been institutionalized, as is evident in the recent United States Public

Table 2. Sampler of honors

\author{
Markle Scholar \\ Merit Award, SUNY \\ Martha May Eliot Award, APHA \\ Gustave Lienhart Award, IOM \\ McDonald Physician's Award \\ Lemuel Shattuck Award \\ Distinguished Fellow, APA \\ Simon Wile Award, AACAP \\ Community Pediatrics Award, AAP \\ Distinguished Service Award, OEO \\ Aldrich Award, AAP
}

\author{
Agnes Grieg Award \\ Myrdal Prize \\ Scientific Award, SRCD \\ USPHS Distinguished Service Medal \\ Massachusetts Service Award \\ AMA-ERF Award in Health Education \\ Camille Cosby World of Children Award \\ Achievement Award, University of Illinois \\ Dolly Madison Award \\ Award, Child Mental Welfare, NYC
}


Health Service review of progress toward the 1990 objectives and the current exercise to update goals for the year 2000. J.B.R. became a spokesman for incorporating health objectives into U.S. foreign policy. There are two portraits from this period. Figure 5 shows him resplendent in an Admiral's uniform, the rank accorded to the Surgeon General. Figure 6 shows J.B.R. in Havana, where he spent several hours commiserating about the insatiable demand for health services in socialist as well as capitalist socities with the Cuban President. You know which one is Julie. The fellow with the beard is Fidel.

In 1981, Dr. Richmond returned to Harvard to take a major role in the newly formed interfaculty Division of Health Policy Research and Education. He served as its Director from 1983 to 1988. Under his leadership, the Division has carried out studies on child health policy, prematurity, adolescent pregnancy, technology assessment, ethical issues in the use of technology, Medicare and Medicaid policy for the 1990s, and the effects of ownership (investor owned versus not-for-profit) on the delivery of mental health care. Now nominally emeritus, my favorite retired professor is heavily involved in epidemiologically oriented studies of infant mortality, chairs an Institute of Medicine/ National Academy of Sciences Forum on the Future of Children and Families, consults to the Carnegie and other foundations, etc. Very recently, with some junior colleagues, Julie has begun the study of the developmental antecedents of habituation.

My time is up. I have been forbidden by the Chair to recite the list of honors Dr. Richmond has received. They are shown in Table 2 . He is, as you can see for yourself, a prophet with honor in his own country.

If Julie were a candidate for public office, I would conclude by stating unequivocally that he has never smoked marijuana, that I've never seen him drunk, and that he doesn't take bimbos to hotel rooms-or any other rooms, for that matter. However, full disclosure compels me to reveal his one sin, one I trust the theologians among you will agree is venial rather than mortal. I am sorry to have to report it. I feel, in all candor, that I must do so. He has a penchant for terrible puns. I do ask that you not judge him too harshly. For, as Joseph Addison wrote in The Spectator (5), "The sins of punning are in the minds of all men, and though they may be subdued by reason, reflection, and good sense, they will be very apt to shoot up in the greatest genius."

\section{REFERENCES}

1. Jacobi A 1889 The President's address: the relations of pediatrics to general medicine. Transactions of the American Pediatric Society VI (11):758-769

2. Richmond JB 1969 Currents in American Medicine: A Developmental View of Medical Care and Education. Harvard University Press, Cambridge

3. Richmond JB 1979 Healthy People: The Surgeon General's Report on Health Promotion and Disease Prevention. U.S. Department of Health, Education, and Welfare, Washington, DC, Publication No. 79-55071

4. Richmond JB 1980 Promoting Health, Preventing Disease: Objectives for the Nation. U.S. Government Printing Office, Washington, DC

5. Addison J 1854 Spectator \#61, Thursday, May 10 (1711). In: Greene GW (ed) The Works of Joseph Addison, Vol 4. Putnam, New York, pp 177-181 